\title{
Multivariate DINEOF Reconstruction for Creating Long-Term Cloud-Free Chlorophyll- $a$ Data Records From SeaWiFS and MODIS: A Case Study in Bohai and Yellow Seas, China
}

\author{
Yueqi Wang (), Zhiqiang Gao, and Dongyan Liu
}

\begin{abstract}
A long-term reliable satellite chlorophyll-a (chl-a) data record is essential in understanding the state of ocean biology and quantifying its changes. Creating a long-term data record requires a combination/merger of multiple satellite products into one data record, since the lifetime of any single ocean color sensor is finite. However, because of differences in sensor design, calibration, and retrieval models, apparent cross-mission biases are usually observed between different sensor products. To attain a coherent multisensor chl- $a$ data record, the observed cross-mission biases should be accurately addressed in the data combination/merging schemes. In this study, a multivariable data interpolating empirical orthogonal functions (M-DINEOF) approach was used to create long-term chl- $a$ records by applying the sea-viewing wide field-of-view sensor and moderate resolution imaging spectroradiometer products. Under the assumption that the single-sensor chl- $a$ product is free from spurious temporal artifacts and can be reference time series representing the actual variability of chl- $a$, the discrepancies of trends derived from different chl- $a$ series were quantitatively evaluated based on statistical $t$-test and Taylor diagram analyses. Compared with direct concatenation and linear regression methods, the M-DINEOF method more effectively reproduced the main trend patterns observed in reference data series during their overlapped periods. The results highlight the importance of a cross-mission bias correction when combining multisensor satellite data records and suggest that the M-DINEOF reconstruction provides a simple and effective path forward for creating reliable multisensor ocean color records suitable for long-term trend analysis.
\end{abstract}

Index Terms-Multisensor data records, multivariable data interpolating empirical orthogonal functions (M-DINEOF) reconstruction, satellite chlorophyll- $a$ product, trend consistency.

Manuscript received March 27, 2018; revised January 30, 2019; accepted March 21, 2019. Date of publication April 25, 2019; date of current version May 25, 2019. This work was supported in part by the National Natural Science Foundation of China under Grants 41706134 and 41876107, in part by NSFC-Shandong joint fund project (U1706219), in part by Aoshan Science and Technology Innovation Program of Qingdao National Laboratory for Marine Science and Technology under Grant 2016ASKJ02, in part by the Strategic Priority Research Program of the Chinese Academy of Sciences (XDA11020702), and in part by the basic Special Program of Ministry of Science and Technology (2014FY210600). (Corresponding author: Yueqi Wang.)

Y. Wang and Z. Gao are with the Yantai Institute of Coastal Zone Research, Chinese Academy of Sciences, Yantai 264003, China (e-mail: yueqiwang@ yic.ac.cn; zqgao@yic.ac.cn)

D. Liu is with the State Key Laboratory of Estuarine and Coastal Research, East China Normal University, Shanghai 200062, China (e-mail: dyliu@ sklec.ecnu.edu.cn).

Color versions of one or more of the figures in this paper are available online at http://ieeexplore.ieee.org.

Digital Object Identifier 10.1109/JSTARS.2019.2908182

\section{INTRODUCTION}

$\mathbf{O}$ VER the past several decades, an increasing number of satellite sensors have been applied to measure ocean color parameters to derive a global view and to conduct time-series analyses of the ocean [1]-[4]. Multiple satellite sensors with similar characteristics provide a synergistic opportunity to improve the spatial and temporal coverage of satellite data records by combining/merging their observations to permit the creation of long-term continuous ocean color data records that can detect multiyear trends over regional and/or global seas [5]-[7]. However, uncertainties associated with sensor design, instrumental calibration, and retrieval algorithms may introduce significant cross-mission biases between multisensor satellite products [8]-[10]. These biases, if not properly addressed, may introduce artifacts in the combined records that may change or even invalidate the conclusions of the dynamic analyses [11], [12]. For instance, some previous studies regarding consistency evaluations between different chlorophyll- $a$ (chl- $a$ ) products concluded that the multisensors combined records are usually capable of capturing accurate relative spatial and seasonal patterns, but caution must be employed when they are used for analyzing interannual variations and multiyear trends studies [10], [11], [13]-[18]. Therefore, in constructing reliable ocean color data records from multisensor observations, the cross-mission biases should be properly addressed and reduced from the combined data records as much as possible.

In recent years, various efforts have been made to merge multisensor datasets to create long-term ocean color data records. From the global ocean perspective, several merged chl- $a$ products have been widely used. For example, the Garver-Siegel-Maritorena chl- $a$ product is developed by the Global Ocean Colour project of the European Space Agency (www.globcolour.info) [16], and the OC-CCI (Ocean ColourClimate Change Initiative) chl- $a$ product is constructed and provided by the Climate Change Initiative of European Space Agency (http://www.esa-oceancolour-cci.org/). However, the global-based products need to be thoroughly validated before being applied in local regions due to the complexity of biooptical property. In regional applications, many schemes have been attempted, from simple binning methods to more sophisticated approaches. In summary, schemes were performed using 
the "final" ocean color product (i.e., chl- $a$ ) by literally combining the observations from different sensors into a new integrated dataset [11], [20], [21], and they can be categorized as productbased statistical approaches; the other schemes were constructed by intermixing observations of the spectral normalized waterleaving radiance $(\operatorname{NLw}(\lambda))$ from different sources into a biooptical model to derive merged records [8], [22], [23], and they can be categorized as spectral-based analytical approaches. In practice, the statistical approaches were more commonly used because the spectral-based methods usually requiring clear $a$ priori knowledge of bio-optical models. These models are not easily acquired and doing so is particularly difficult in optically complex waters. Specifically, the most widely used statistical merging approaches include simple examples, such as direct concatenation [3], [24], [25], linear regression [26], [27], and weighted averaging approaches [28], as well as higher skill examples, such as nonlinear regression [29], [30], objective analysis [28], [31], spectral information adaptation, and synthesis schemes [32]. All these statistical approaches are highly dependent on the calibration models (e.g., linear of nonlinear) in relating multisensors observations. When the predefined models are incapable of clearly expressing the relationship between these products, the results of the combination may be inaccurate. In this context, we considered that some of the self-organization and parameter-free approaches might solve these dilemmas.

In this study, a multivariate data interpolating empirical orthogonal functions (M-DINEOF) approach was examined to overcome these barriers for multisensor data combinations. The M-DINEOF method is an extension of ordinary DINEOF method with an additional consideration of relevant information between different variables [33]. DINEOF is an empirical orthogonal functions (EOF)-based method used to reconstruct missing data in geophysical datasets [34], [35]. The DINEOF can be used to reconstruct monovariate datasets (such as sea surface temperature or chl- $a$, etc.) [35], and can also be used to reconstruct multivariate data sets with little increase in complexity [33]. In multivariate reconstructions, extended EOF is used that considers the interrelationships between related variables and infer data at missing locations.

The focus of this study is on the comparisons of trend estimates obtained from multisensor combined data series with those from the single-sensor data series. Our rationale is that the trend estimates from the combined time series should be consistent with those of all successive single-sensor time series when computed over their overlapped time periods. If this is the case, it might be prudent to conduct climate research on the time scales allowed by the combined datasets. In contrast, however, the occurrences of trends from a multisensor combined record that significantly differ from those of a single-sensor record indicate that undesirable artifacts have been introduced into the construction of the combined dataset and that its status as a climate data record is questionable. This reasoning relies on the assumption that single-sensor products can be treated as reference time series free from temporal artifacts such as drifts from an insufficiently characterized calibration. There is a solid basis for using single-sensor products as reliable reference series; this is supported by the efforts made to calibrate the instruments

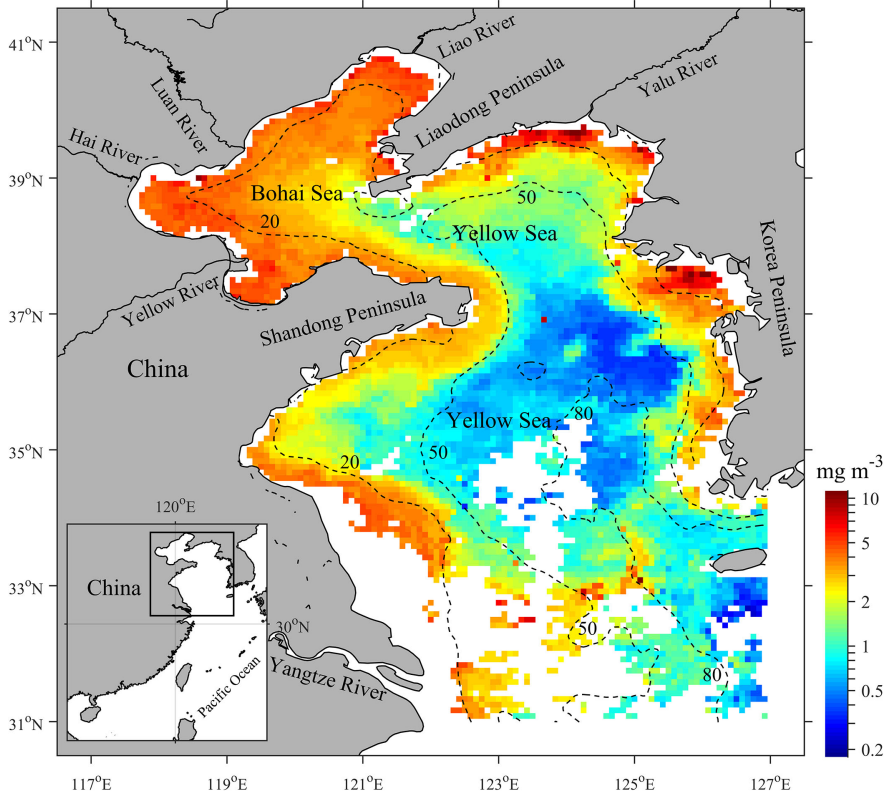

Fig. 1. Location of the Bohai Sea and Yellow Sea (BYS). The dash lines indicate isobaths and the color map shows the monthly composited SeaWiFS sea surface chl- $a$ concentration in September 1997.

and to maintain their stability over time, although some caution should still be exercised [13], [36], [37].

The objectives of this paper are as follows:

1) To quantify the consistency of trend estimates obtained from different combined datasets with those from reference datasets.

2) To examine the M-DINEOF approach that can be applied in combination with SeaWiFS and MODIS chl- $a$ datasets to reconstruct temporally extended and spatially cloudfree chl- $a$ data records.

\section{Materials AND MethodS}

\section{A. Study Area}

The Bohai and Yellow Seas (hereafter, BYS) are typical marginal seas located in northern China and surrounded by the mainland of China and the Korean Peninsula (see Fig. 1). Most of the BYS consists of shallow continental shelf (water depth $<100 \mathrm{~m}$ ), and numerous rivers from the Chinese and Korea continents flow into the seas. The coastal zone of the BYS is an area of environmental and economic importance to China, thus there has much attention been paid on the variability of marine phytoplankton biomass based on in situ and remote sensing observations. To date, a number of remotely sensed studies of chl- $a$ variations have been conducted in the BYS, in terms of spatial distribution, seasonal variability, and interannual changes [25], [38]-[40]. For instance, the magnitude of sea surface chl- $a$ in coastal waters was generally higher than that in offshore water, the seasonality of sea surface chl- $a$ presents distinct spatial heterogeneity and the interannual variations of sea surface chl- $a$ were also quite different between different subregions [35], [39]. Generally, to support long-term chl- $a$ trend 


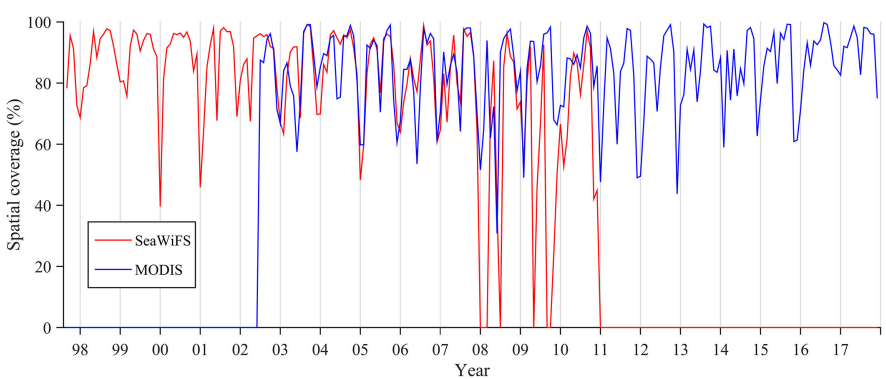

Fig. 2. Time series of spatial coverage for the original SeaWiFS and MODIS monthly chl- $a$ images over the BYS.

analysis in the BYS, simple methods such as direct concatenation [25] and linear regression [26], [41] were commonly used for multisensor products combination in order to produce temporally extended and continuous chl- $a$ data records. However, if cross-mission biases are temporally and spatially heterogeneous, these simple methods may be not capable of addressing all the biases effectively. Therefore, we proposed to test the MDINEOF method in this region, and its performance was only compared with simple combination methods including concatenation and linear regression.

\section{B. Satellite Chl-a Data Sources}

Standard mapped satellite images of sea surface chl- $a$ concentration derived from sea-viewing wide field-of-view sensor (SeaWiFS) and the moderate resolution imaging spectroradiometer (MODIS) on the Aqua satellite were used in this study. These satellite images were obtained from the Ocean Biology Processing Group of the Goddard Space Flight Center (GSFC) (http://oceancolor.gsfc.nasa.gov/) in netCDF format (network Common Data Form) with $9 \mathrm{~km}$ resolution cylindrical equidistant grids. The basic algorithm described by O'Reilly et al. [42] was used for calculating sea surface chl- $a$ concentration. The monthly averaged SeaWiFS images from September 1997 to December 2010 and MODIS images from July 2002 to December 2017 for the geographic area covered by $117-127^{\circ} \mathrm{E}$ and $31-41^{\circ} \mathrm{N}$ were extracted. After the land masking and low temporal coverage $(<10 \%$ for both of SeaWiFS and MODIS data) pixels eliminating, 7391 pixels were conserved in each image for both of the two datasets. The temporal variations in the percentages of spatial coverage for the SeaWiFS and MODIS monthly chl- $a$ datasets over the BYS were shown in Fig. 2. On one hand, there are apparent spatial missing data in both chl- $a$ datasets with spatial coverage lower than $100 \%$. On the other hand, the combination of the two datasets enables to constructing extended data records with time continuity in the period of 1997-2017.

A multimission satellite-derived sea surface chl- $a$ dataset from the Ocean Colour CCI (OC_CCI, Version 3, CCI, 2011) project (http://www.esa-oceancolour-cci.org/) was also used for trend comparisons [43]. This product merges data from the SeaWiFS, MODIS, medium resolution imaging spectrometer, and visible infrared imaging radiometer suite satellite sensors to create a continuous, bias-corrected data series running from

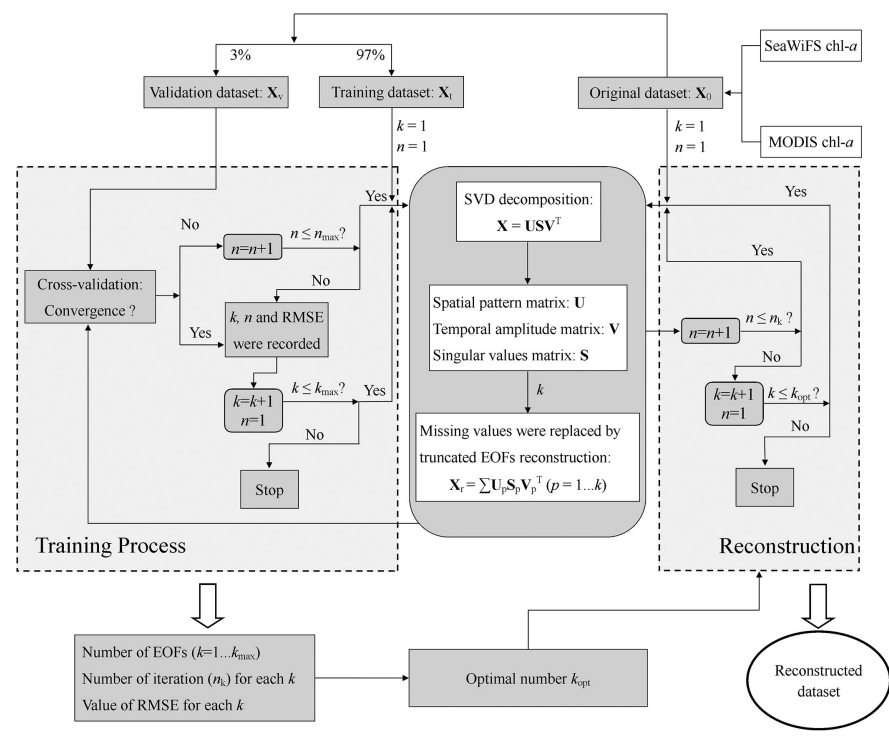

Fig. 3. Schematic flowchart of the DINEOF reconstruction.

September 1997 to December 2016 inclusive. Band-shifting and bias-correction techniques are used to combine the data from individual sensors. The band-shifting is performed using a bio-optical model inversion with SeaWiFS reflectance as a reference and other sensors data were shifted to the nearest SeaWiFS bands [23]. The bias-correction is performed by adjusting pixel-level radiances to reduce the difference between SeaWiFS and the other sensors [44]. Then, the chl- $a$ values were derived from the merged $R_{r s}$ by the maximum-band-ratio algorithm OC4v6 [42]. In this study, level 3, mapped data were acquired at a spatial resolution of $9 \mathrm{~km}$ and monthly temporal resolutions for the period January 1998-December 2016.

\section{Algorithm of Ordinary DINEOF Reconstruction}

The DINEOF method is a widely used self-consistent method for the reconstruction of missing data in geographic datasets [33], [34], [45]. A schematic flowchart is presented in Fig. 3 to demonstrate the DINEOF reconstruction scheme. The main procedures are summarized as follows:

1) The original dataset $\left(\mathbf{X}_{0}\right)$ was organized as a pseudo twodimensional (2-D) matrix, where the rows represent the series of spatial pixels, and columns represent the successive scenes of temporal steps.

2) $3 \%$ of the existing data in the matrix $\mathbf{X}_{0}$ was randomly selected and initially set aside (deemed as missing) for progressive cross-validation $\left(\mathbf{X}_{v}\right)$. The remaining $97 \%$ of the data was used in the training process to obtain the optimal number of EOF modes $\left(\mathbf{X}_{t}\right)$.

3) Prior to input for EOF decomposition ( $\mathbf{X}$ in Fig. 3), the global mean of all existing data is calculated and subtracted from the value of each existing data. Meanwhile, all the missing values in $\mathbf{X}$ were initially set to zeros.

4) The EOF decomposition is performed on $\mathbf{X}$ by the singular value decomposition (SVD) method, and the spatial EOFs (U), singular values matrix (S), and temporal EOFs (V) 
obtained

$$
\mathbf{X}=\mathbf{U S V}^{T} .
$$

Thus, the missing data can be replaced by a truncated series of EOFs

$$
X_{i, j}=\sum_{p=1}^{k} S_{p}\left(U_{p}\right)_{i}\left(V_{p}^{T}\right)_{j}
$$

where $\mathbf{X}_{i, j}$ is the missing data, and $i, j$ are the spatial and temporal indices of the missing data; $\mathbf{U}_{p}$ and $\mathbf{V}_{p}$ are the $p$ th column of the spatial and temporal EOFs, respectively; $\mathbf{S}_{p}$ is the $p$ th singular value, and $k$ is the number of EOF modes used for reconstruction.

5) The first SVD decomposition was performed on $\mathbf{X}_{t}$, and the missing data can be replaced by (2) with $k=1$. Meanwhile, the values of $\mathrm{X}_{v}$ can also be calculated by (2) with $k=1$, and the relative mean squared error (RMSE) between EOFs calculated and original values of $\mathbf{X}_{v}$ can be estimated. Then, another SVD decomposition was performed on the new $\mathbf{X}_{t}$ (with missing values updated from the last decomposition), and the missing values in $\mathbf{X}_{t}$ and $\mathbf{X}_{v}$ are replaced by (2) with $k=1$ ocean again. The RMSE between the recalculated and original values of $\mathbf{X}_{v}$ can then be estimated once again. This iteration continues to produce improved calculations for the missing data and improved EOF until the convergence criterion is reached (the cross-validation RMSE between previous and current iterations is smaller than the threshold value of $1.0 \mathrm{e}-5$ ). To avoid an infinite loop, the maximum number of iterations is set to 100 ( $n \leq 100 \mathrm{in} \mathrm{Fig.} \mathrm{3).} \mathrm{Once} \mathrm{the} \mathrm{iterations} \mathrm{stop,}$ the cross-validation RMSE and the number of iterations ( $n_{k}$ in Fig. 3) corresponding to $k$ is recorded.

6) After the convergence is reached with $k=1$, the procedures (4) and (5) are repeated with $k=2,3 \ldots k_{\max }$, successively. $k_{\max }$ is the predefined maximum number of EOFs. As a result, the number of iterations $\left(n_{k}\right)$ and the cross-validation RMSE for each $k$ were obtained. Then, the optimal number of truncated EOFs $\left(k_{\mathrm{opt}}\right)$ is reached when the minimum RMSE is obtained.

7) Once the optimal number of EOFs $\left(k_{\mathrm{opt}}\right)$ is determined, the procedure (4) was iteratively performed on the original dataset $\left(\mathbf{X}_{0}\right)$ with $k=1 \ldots$ and $k_{\text {opt }}$ using the recorded $n_{k}$ corresponding to each $k$. Finally, values for all pixels are reconstructed by truncated EOF modes using (2).

This is a general description of how the DINEOF method works. For a more detailed description, see [34], [35], and [45].

\section{Algorithm of Multivariable DINEOF Reconstruction}

M-DINEOF is an extended form of the ordinary DINEOF method, in which multiple variables are combined to perform an EOF decomposition and reconstruction [33], [34]. Compared with the ordinary DINEOF method (see Section II-C), only the organization of the input dataset was modified in the MDINEOF method. In this study, the SeaWiFS and MODIS chl- $a$ images were organized in two pseudo 2-D matrices $\mathbf{X}_{s}$ and $\mathbf{X}_{m}$, respectively. In each matrix, the rows represent the series of spatial pixels, and the columns represent successive scenes of monthly steps. Then, a combined matrix $\left(\mathbf{X}_{0}\right)$ is constructed as follows:

$$
X_{0}=\left[\begin{array}{c}
\mathbf{X}_{s} \\
\mathbf{X}_{m}
\end{array}\right]
$$

where $\mathbf{X}_{s}$ and $\mathbf{X}_{m}$ are the SeaWiFS and MODIS chl- $a$ matrices, respectively. As a combination, $\mathbf{X}_{s}$ and $\mathbf{X}_{m}$ can have a different number of rows, but must have the same number of columns. $\mathbf{X}_{0}$ contains both existing and missing values.

In this study, both time spans of $\mathbf{X}_{s}$ and $\mathbf{X}_{m}$ were fixed to the period from September 1997 to December 2017, with 244 monthly steps. Since there was no data coverage for the MODIS dataset from September 1997 to June 2002 nor for the SeaWiFS dataset from January 2011 to December 2017, all the pixels from column 161 to column 244 in $\mathbf{X}_{s}$ and column 1 to column 58 in $\mathbf{X}_{m}$ were set to missing values. As a result, the sizes of $\mathbf{X}_{s}, \mathbf{X}_{m}$, and $\mathbf{X}_{0}$ were $7391 \times 244,7391 \times 244$, and $14782 \times 244$, respectively. Then, procedures (2)-(7) of the DINEOF algorithm (see Section II-C) were performed on the new combined data $\mathbf{X}_{0}$ and all the values were reconstructed by truncated EOF modes. As a result of the M-DINEOF reconstruction on the SeaWiFS and MODIS chl- $a$ datasets, two gap-free datasets were reconstructed. One resembles SeaWiFS (SeaWiFS-resembling), in which data series after December 2010 were estimated by truncated EOF modes. The other one resembles MODIS (MODIS-resembling) in which the data series before July 2002 were estimated by truncated EOF modes.

\section{E. Constructions of Different Chl-a Data Series}

With the data coverages in the SeaWiFS and MODIS chl- $a$ datasets (see Fig. 2), the two datasets must be reasonably combined to obtain a temporally continuous chl- $a$ series over the period from September 1997 to December 2017. In practice, when setting SeaWiFS data as a benchmark, the data series from January 2011 to December 2017 must be constructed with an understanding of the MODIS data. When MODIS data is benchmark, the data series from September 1997 to June 2002 must be constructed with an understanding of the SeaWiFS data. In this study, four merged products were examined and compared with the reference, including products generated by direct concatenation, linear regression, M-DINEOF reconstruction, and OC-CCI products. Fig. 4 shows the structures of each dataset. Specifically, five types of chl- $a$ series were constructed as follows:

1) Reference chl- $a$ dataset $\left(D_{\text {ref }}\right)$ : The original SeaWiFS chl- $a$ from January 1998 to December 2010 ( $D_{\text {ref }}$ from 1998 to 2010) and the original MODIS chl- $a$ from January 2003 to December 2016 ( $D_{\text {ref }}$ from 2003 to 2016) were selected as two independent reference datasets.

2) Concatenated chl- $a$ dataset $\left(D_{\text {con }}\right)$ : The original SeaWiFS chl- $a$ from January 1998 to December 2002 were concatenated with the original MODIS chl- $a$ from January 2003 to December 2010, thereby constructing a temporally continuous chl- $a$ series from January 1998 to December 2010 ( $D_{\text {con }}$ from 1998 to 2010); the original SeaWiFS chl- $a$ 


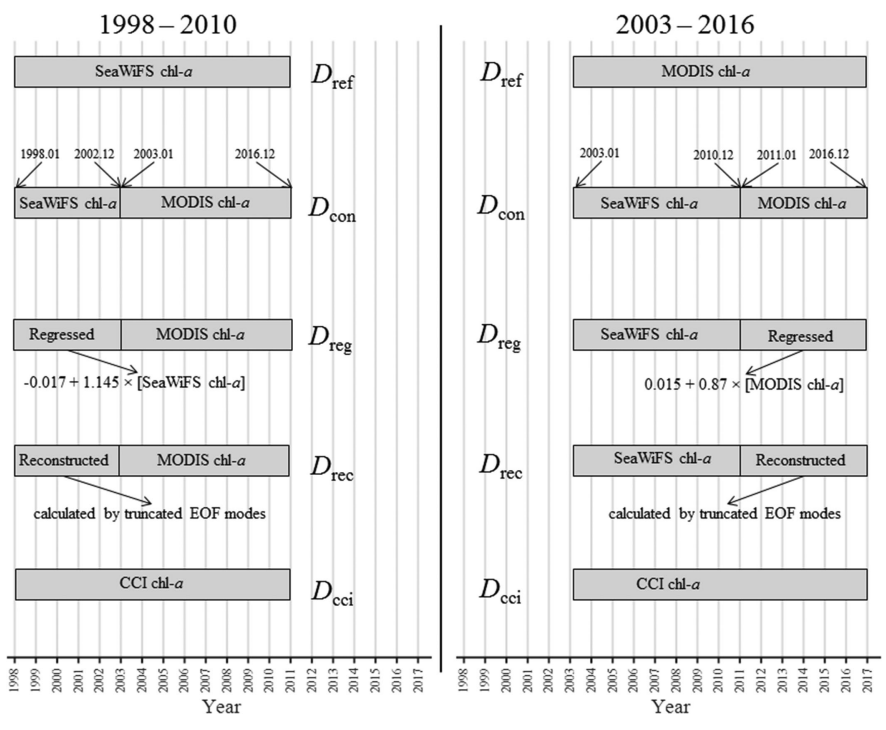

Fig. 4. Structures of different chl- $a$ datasets constructed for trends comparisons.

from January 2003 to December 2010 were concatenated with the original MODIS chl- $a$ data from January 2011 to December 2016 to construct a temporally continuous chl- $a$ data series from January 2003 to December 2016 ( $D_{\text {con }}$ from 2003 to 2016).

3) Regressed chl- $a$ dataset $\left(D_{\text {reg }}\right)$ : The original SeaWiFS chl- $a$ were transformed to resemble MODIS chl- $a$ values by using linear regression to generate regressed SeaWiFS chl $-a$ values. Then, the regressed SeaWiFS chl- $a$ from January 1998 to December 2002 were concatenated with the original MODIS chl- $a$ from January 2003 to December 2010 to construct a temporally continuous chl- $a$ series from January 1998 to December $2010\left(D_{\text {reg }}\right.$ from 1998 to 2010); the original MODIS chl- $a$ were transformed to resemble SeaWiFS values using linear regression to generate regressed MODIS chl- $a$ values. Then, the regressed MODIS chl- $a$ from January 2011 to December 2016 were concatenated with the original SeaWiFS chl- $a$ from January 2003 to December 2010 to construct a temporally continuous chl- $a$ series from January 2003 to December 2016 ( $D_{\text {reg }}$ from 2003 to 2016).

4) Reconstructed chl- $a$ dataset $\left(D_{\text {rec }}\right)$ : The M-DINEOF reconstructed SeaWiFS-resembling chl- $a$ from January 1998 to December 2010 ( $D_{\text {rec }}$ from 1998 to 2010$)$ and the M-DINEOF reconstructed MODIS-resembling chl- $a$ data from January 2003 to December 2016 ( $D_{\text {rec }}$ from 2003 to 2016) were selected as the reconstructed chl- $a$ series.

5) CCI chl- $a$ dataset $\left(D_{\text {cci }}\right)$ : The CCI merged chl- $a$ from January 1998 to December 2010 ( $D_{\text {cci }}$ from 1998 to 2010) and from January 2003 to December 2016 ( $D_{\text {cci }}$ from 2003 to 2016) were selected and compared with other datasets.

After all the five datasets were constructed, the ordinary DINEOF was applied to each dataset for reconstructing spatially cloud-free images to eliminate the impact of missing values on trend estimates and comparisons between chl- $a$ time series.

\section{F. Trend Detection in Chl-a Time Series}

The Mann-Kendall's test was used to evaluate the significance of the monotonic trend the in chl- $a$ time series, and the magnitude of trend was estimated by Sens's method [46], [47]. As a robust and nonparametric method, the Mann-Kendall's test has been widely used in identifying sea surface chl- $a$ trends in previous studies [48], [49]. The test is based on the computation of a suite of Mann-Kendall statistics (S) applied to each separated month $m$, which is then combined to determine on the presence of long-term monotonic changes in the original time series [50]; the $S$ is defined as follows:

$$
\begin{array}{r}
\mathbf{S}=\sum_{i=1}^{n m-1} \sum_{j=i+1}^{n m} \operatorname{sgn}\left(x_{j m}-x_{i m}\right) \\
\operatorname{sgn}\left(x_{j m}-x_{i m}\right)=\left\{\begin{array}{lll}
1 & \text { if } & x_{j m}-x_{i m}>0 \\
0 & \text { if } & x_{j m}-x_{i m}=0 \\
-1 & \text { if } & x_{j m}-x_{i m}<0
\end{array}\right.
\end{array}
$$

where $x$ are the values of the time series, and $n m$ is the amount of data for the month $m$.

Then, under the null hypothesis and for a large dataset, a normal distribution of mean 0 and variance $\operatorname{Var}(\mathbf{S})$, the statistical significance of the test is indicated by the $\mathbf{Z}$ value, defined as follows [50]:

$$
\mathbf{Z}=\left\{\begin{array}{ccc}
\frac{S-1}{\sqrt{\operatorname{Var}(S)}} & \text { if } & S>0 \\
0 & \text { if } & S=0 \\
\frac{S-1}{\sqrt{\operatorname{Var}(S)}} & \text { if } & S<0 .
\end{array}\right.
$$

A positive value for $\mathrm{Z}$ indicates a monotonic upward trend, while a negative value reveals a downward trend in the series. If $|\mathbf{Z}|$ is greater than $Z_{1-\alpha / 2}$ at the chosen significance level $\alpha$, the trend is significant. The trend magnitude (i.e., slope) can be determined as the median of individual slopes:

$$
\beta=\operatorname{median}\left[\frac{x_{j m}-x_{i m}}{j-i}\right] .
$$

To better highlight the chl- $a$ trend over the entire study period, we provide the results in terms of relative changes (i.e., $\%$ year $^{-1}$ ) by dividing $\beta$ for the climatological values. The climatological values were calculated as the median of the entire chl- $a$ series.

\section{G. Statistical Comparison of Trends From Different Chl-a Series}

Trend estimates obtained from two different data series can be compared with a statistical $t$-test [29], [36]. Considering the slope $\beta_{1}$ and $\beta_{2}$ associated with two data series estimated from Sen's method, a $t$-test was used to establish if $\beta_{1}$ and $\beta_{2}$ could be considered equal (null hypothesis $H_{0}$ ) with a level of significance $P$ : when $P$ was low than 0.05 , this hypothesis could be rejected, and the slopes were considered significantly different. The $t$-test relied on the following value:

$$
t=\frac{\beta_{1}-\beta_{2}}{\sqrt{s_{\beta, 1}^{2}+s_{\beta, 2}^{2}}}
$$


with a degree of freedom $d f$ equal to

$$
d f=\frac{\left(s_{\beta, 1}^{2}+s_{\beta, 2}^{2}\right)^{2}}{\frac{1}{N_{1}} s_{\beta, 1}{ }^{4}+\frac{1}{N_{2}} s_{\beta, 2}}
$$

where $N_{1}$ and $N_{2}$ are the number of samples in each data series, respectively. The $s_{\beta, 1}$ and $s_{\beta, 2}$ are the standard error of the associated slope $\beta_{1}$ and $\beta_{2}$, respectively. The standard error of the slope $\beta$ is written as Sokal Robert and James [51]:

$$
s_{\beta}=\sqrt{\frac{1}{(N-2)}\left(\frac{\sigma(y)^{2}}{\sigma(x)^{2}}-\beta\right)}
$$

where $x$ and $y$ represent the $N$-element series associated with time and chl- $a$ data, respectively, and $\sigma$ indicates the standard deviation operator.

\section{H. Comparison of Trend Patterns From Different Datasets}

To compare the spatial patterns of trends from different chl- $a$ datasets, Taylor diagrams [2] were used to visualize statistical figures in the same summary plots. The Taylor diagrams provide a way of graphically summarizing how closely a pattern (or a set of patterns) matches reference pattern. The similarity between two patterns is quantified in terms of their correlation coefficient, their standard deviations, and their unbiased root mean square error. In the Taylor plot, the reference pattern is presented by a point on the $x$-axis of the 2-D diagram by the standard deviation; each comparing pattern is represented by a point in the polar coordinate system $(d, \theta)$. The radial distance $d$ from the origin indicates the standard deviation, the cosine of the angle $\theta$ between the direction of a data point location and the $x$-axis indicates the correlation coefficient, and the distance between the reference and a point is the unbiased root mean square error. The closer a pattern point is to the reference point, the more similar it is to the reference pattern.

\section{RESULTS}

\section{A. Comparisons of Chl-a Between SeaWiFS and MODIS}

In this section, the original SeaWiFS and MODIS chl- $a$ values were compared using their concurrent chl- $a$ observations over the year 2002-2010. The matchup analysis, cross-mission bias description, and trend assessment were used for evaluations.

1) Matchup Comparison: A quantitative comparison between the MODIS and SeaWiFS concurrent chl- $a$ is presented in Fig. 5. Overall, the coefficient of determination $\left(R^{2}\right)$ for linear regression is 0.80 , which is statistically significant ( $p$-value $<0.01$ ); the RMSE is 0.16 , which is smaller than the intrinsic chl- $a$ algorithm "noise" of RMSE $=0.22$ [42], thus indicating that SeaWiFS and MODIS chl- $a$ compare reasonably well across their entire range. However, the non-one slope $(0.87)$ and non-zero intercept (0.02) of the fitted line (using type II linear regression [53]), which are associated with the positive bias (0.02), indicate that there are nonnegligible differences between SeaWiFS and MODIS chl- $a$; the values of SeaWiFS chl- $a$ product appear higher in the low intervals and lower in the high intervals compared to the MODIS chl- $a$ values.

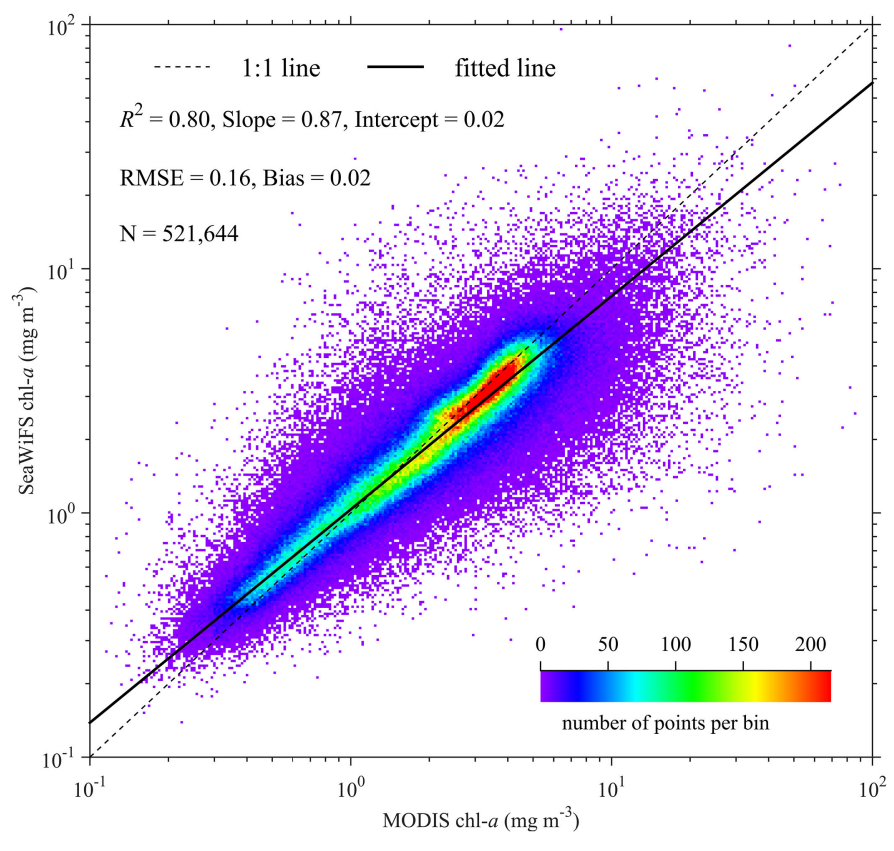

Fig. 5. Scatter plot of the concurrent chl- $a$ values extracted from SeaWiFS and MODIS products in the BYS. Color scale indicates the density function.

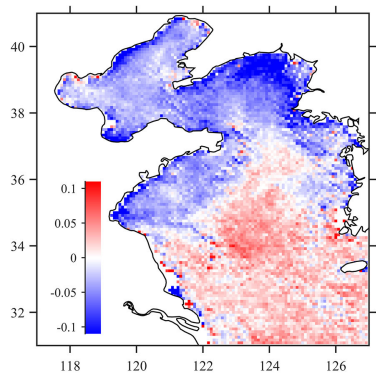

(a)

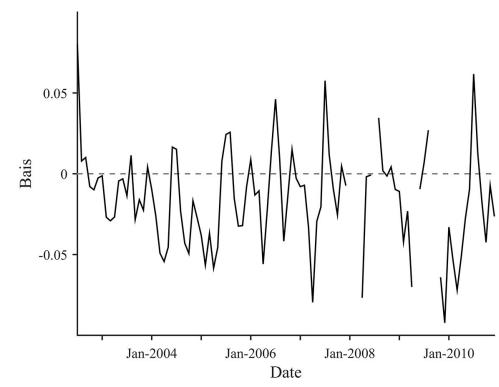

(b)
Fig. 6. (a) Spatial distribution of time-averaged biases. (b) Time series of basin-averaged biases between original SeaWiFS and MODIS chl- $a$ products.

2) Characteristic of the Cross-Mission Bias: The difference between the SeaWiFS and MODIS chl- $a$ in terms of spatial distribution and time series variability are shown in Fig. 6. Fig. 6(a) shows negative biases in the northern basin of the study region, and positive biases over the southern part; the time series present an obvious fluctuation that generally shows weak positive values in summer and strong negative values in other seasons [see Fig. 6(b)]. Meanwhile, the biases present increasing an amplitude from 2003 to 2010 [see Fig. 6(b)], which were also reported in [54] and [17], might occur due to the aging of the sensors [55]. In summary, the biases between SeaWiFS and MODIS chl- $a$ are characterized by uneven distributions across the basin as well as throughout the operational period.

3) Assessment of Multiyear Trends: The trends for the SeaWiFS and MODIS chl- $a$ series were calculated in their overlapped period (September 2002 to December 2010) and shown in Fig. 7(a) and (b), and the significance of the differences between the trends from SeaWiFS and MODIS chl- $a$ series was 


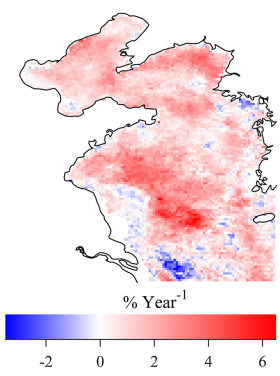

(a)

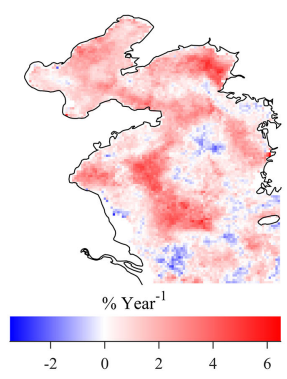

(b)

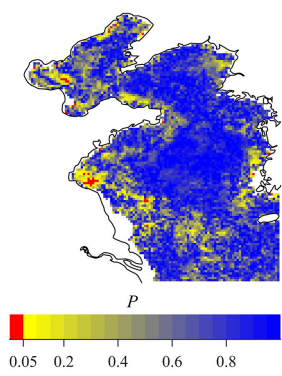

(c)
Fig. 7. Maps of trend calculated from (a) SeaWiFS and (b) MODIS chl- $a$ anomalies in their overlapped period from September 2002 to December 2010. (c) Map of the significance of the $t$-test comparing the trend estimates from SeaWiFS and MODIS chl- $a$ series.

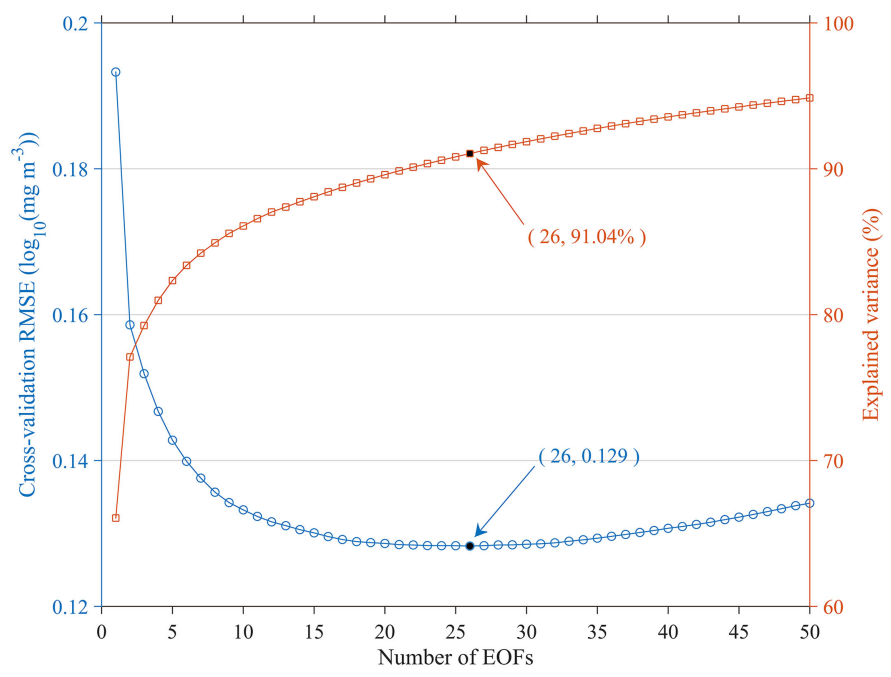

Fig. 8. Cross-validation RMSE and cumulative explained variance for the M-DINEOF reconstruction. The convergence point is shown and the bracketed text gives the optimal number of EOFs as well as the corresponding values.

illustrated in Fig. 7(c). The trends obtained from the SeaWiFS and MODIS chl- $a$ series exhibit a nearly consistent distribution of multiyear trends over the period, with only $\sim 0.5 \%$ of the basin present significant difference of trends $(P<0.05)$.

\section{B. Result of the M-DINEOF Reconstruction}

1) Convergence Process and Validation: Fig. 8 shows the cross-validation process as well as the variability of the cumulative explained variance. There are $26 \mathrm{EOF}$ modes (RMSE $=$ 0.13 ) that were determined by the cross validation to be used for the reconstruction, and they account for more than $91 \%$ of total chl- $a$ variability. Fig. 9 shows the density scatter plots of the original values versus reconstructed values of all valid pixels for SeaWiFS and MODIS chl- $a$ products, respectively. Both the RMSE values obtained from SeaWiFS (RMSE $=0.09)$ and MODIS (RMSE $=0.11$ ) are much smaller in magnitude than the intrinsic "noise" (RMSE $=0.22)$ of the standard chl- $a$ algorithm [42], [46]. The 1:1 fitted line and the relatively low biases $(<0.1)$ between the original and reconstructed chl- $a$ values

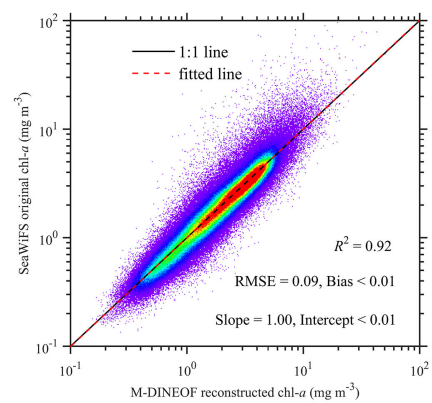

(a)

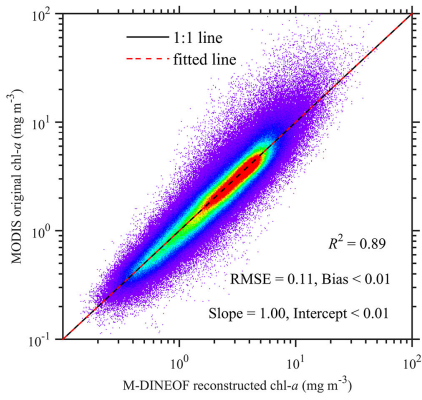

(b)
Fig. 9. Comparison of (a) original SeaWiFS chl- $a$ data with M-DINEOF reconstructed chl- $a$ data, and (b) original MODIS chl- $a$ with M-DINEOF reconstructed chl- $a$ data. The validation parameters are also shown in the text and the color scale of points indicate the density function.

further demonstrated that the M-DINEOF reconstruction acquires reliable results.

2) Dominant EOFs Retained for M-DINEOF Reconstruction: The chl- $a$ signal was optimally synthesized by MDINEOF when using 26 modes, thus accounting for a total of $91.04 \%$ of the input signal variability. The first (1st) and the last modes (26th) are given in the examples illustrated in Fig. 10, together with the corresponding parameter representing the variability of the original signal explained by each EOF mode. The first temporal mode accounts for approximately $66 \%$ of the total variability and is clearly a seasonal signal, with high values in summer and low values in winter [see Fig. 10(c)]. The spatial patterns for the SeaWiFS-resembling and MODIS-resembling datasets of the 1st EOF are nearly consistent $\left(R^{2}=0.97\right.$, $\mathrm{RMSE}=0.0015)$ and generally present positive values in coastal regions, whereas negative values are shown in offshore regions [see Fig. 10(a) and (b)]. The 1st EOF mode is related to the most prominent chl- $a$ seasonality over the BYS [25]. The 26th EOF accounts for $0.22 \%$ of the signal variability and represents complex spatial-temporal modulations. The spatial patterns for the SeaWiFS-resembling and MODIS-resembling datasets of the 26th EOF present moderate consistency $\left(R^{2}=0.21\right.$, RMSE $=0.0091$ ), with some randomly positive and negative patches [see Fig. 10(d) and (e)].

\section{Assessment of Trends in Different Chl-a Datasets}

After having provided background information on the relative agreement between SeaWiFS and MODIS chl- $a$ products, the study now focuses on the trends' estimations from different combined chl- $a$ datasets. First, the trend of each pixel was estimated as the Sen' slope on the monthly chl- $a$ series (see Section II-F). Then, the trends from different datasets were compared with the references on a pixel-by-pixel basis using the statistical $t$-test (see Section II-G). Finally, the spatial patterns of trends calculated from the different datasets were compared overall by Taylor diagrams.

1) Trends Estimation: Trends obtained from the five constructed chl- $a$ datasets ( $D_{\text {ref }}, D_{\text {con }}, D_{\text {reg }}, D_{\text {rec }}$, and $\left.D_{\text {cci }}\right)$ from 1998 to 2010 and 2003 to 2016 (see Fig. 4) are presented in 
EOF $1: 66.05 \%$

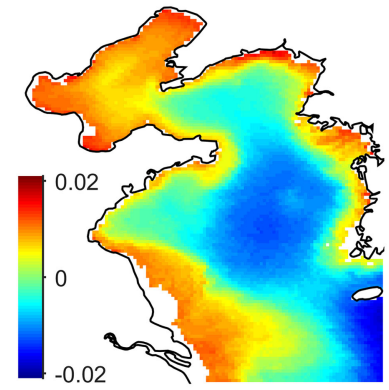

(a)

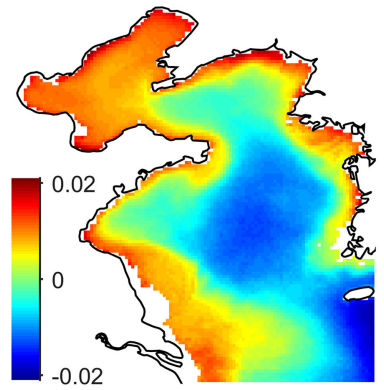

(b)

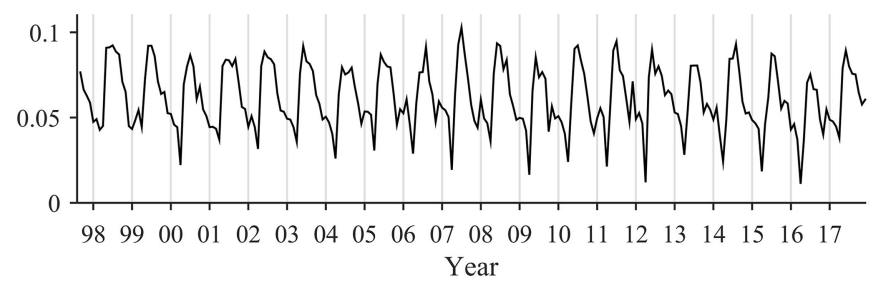

(c)

EOF $26: 0.22 \%$

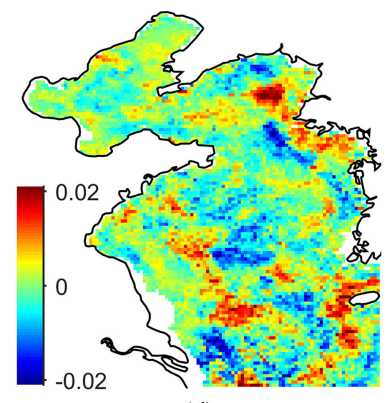

(d)

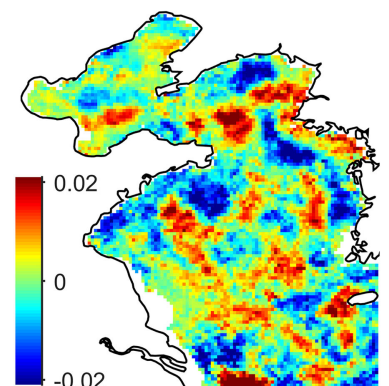

(e)

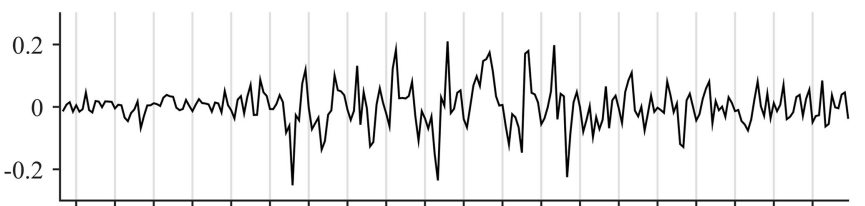

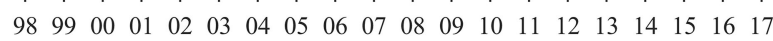
Year

(f)

Fig. 10. First (1st) and last (26th) EOF modes used for M-DINEOF reconstruction. (a) and (b) Spatial pattern for the 1st EOF mode. (c) Temporal mode for the 1st EOF. (d) and (e) Spatial pattern for the 26th EOF mode. (f) Temporal mode for the 26th EOF.

Fig. 11[(a)-(e)] and Fig. 11[(f)-(j)], respectively. Trends for the $D_{\text {ref }}$ from 1998 to 2010 and 2003 to 2016 are deemed as actual trends and are presented in Fig. 11(a) and (f), respectively. Significant positive trends are generally in offshore waters, while no significant trends are observed over most coastal regions [see Fig. 11(a) and (f)]. The extreme positive trends in the central Yellow Sea are of major importance, as they appeared consistent with the observations of microalgae blooms [57]-[60]. The trends obtained from four combined datasets $\left(D_{\text {con }}, D_{\text {reg }}, D_{\text {rec }}\right.$, and $D_{\text {cci }}$ ) from 1998 to 2010 and 2003 to 2016 are presented in Fig. 11[(b)-(e)] and Fig. 11[(g)-(j)], respectively. In the compar-

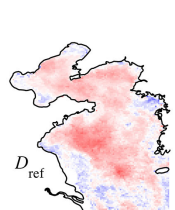

(a)

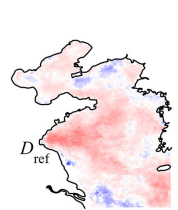

(f)

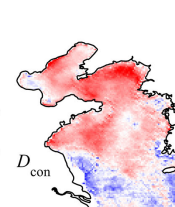

(b)

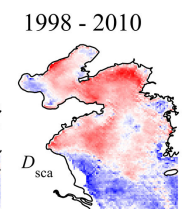

(c)

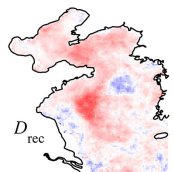

(d)

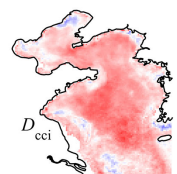

(e)

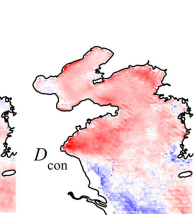

(g)

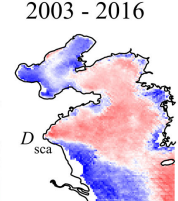

(h)

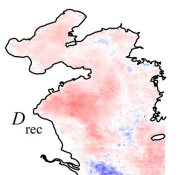

(i)

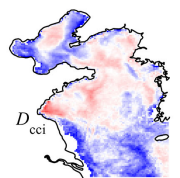

(j)

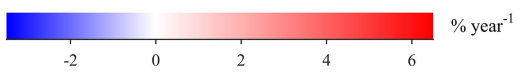

Fig. 11. Trends for (a) $D_{\text {ref }}$, (b) $D_{\text {con }}$, (c) $D_{\text {reg }}$, (d) $D_{\text {rec }}$, and (e) $D_{\text {cci }}$ over the period from January 1998 to December 2010. Trends for (f) $D_{\text {ref }},(\mathrm{g}) D_{\text {con }}$, (h) $D_{\text {reg }}$, (i) $D_{\text {rec }}$, and (j) $D_{\text {cci }}$ over the period from January 2003 to December 2016.

isons, the $D_{\text {rec }}$ [see Fig. 11(d) and (i)] achieved more consistent trends with $D_{\text {ref }}$ [see Fig. 11(a) and (f)] than with $D_{\text {con }}$ [see Fig. 11(b) and (g)] and $D_{\text {reg }}$ [see Fig. 11(c) and (g)]. The trends of $D_{\text {con }}$ and $D_{\text {reg }}$ exhibit striking difference compared to the trends for $D_{\text {ref }}$; not only are there strong positive values over offshore waters, but they also have some patches with significant negative values in coastal regions and near the Yangtze River Estuary (see Fig. 11). Overall, the comparisons showed that trends derived from the M-DINEOF reconstructed chl- $a$ datasets $\left(D_{\text {rec }}\right)$ are the most similar with the actual datasets $\left(D_{\text {ref }}\right)$.

2) Statistical t-Test of Trends: For each pair of reference and combined datasets, the level of significance $P$ of the $t$-test comparing trend slopes, as introduced in Section II-G, quantifies the degree to which two trend estimates differ. In the description of results, the value of $P$ is considered as a measure of the difference between two slopes of linear trends: the smaller the $P$ is, the more the slopes differ, and $P<0.05$ indicates a significant difference between them. Fig. 12 illustrates the $P$ distribution for the comparison of trends derived from the referenced dataset $\left(D_{\text {ref }}\right)$ versus those from four testing datasets ( $D_{\text {con }}, D_{\text {reg }}, D_{\text {rec }}$, and $D_{\text {cci }}$ ) over their common period. In the maps of $D_{\text {ref }}$ versus $D_{\text {rec }}$ [see Fig. 12(c) and (g)], $P$ values appear low only in scattered and small patches, with $2.5 \%$ and $2.2 \%$ of the domain having significant differences $(P<0.05)$ during 1998-2010 and 2003-2016, respectively. However, $P$ values in the maps of $D_{\text {ref }}$ versus $D_{\text {con }}$ [see Fig. 12(a) and (e)] contain $20.1 \%$ and $10.8 \%$ of the domain with low values $(P<0.05)$ during 1998-2010 and 2003-2016, respectively. Meanwhile, $P$ values from trends of $D_{\text {ref }}$ versus $D_{\text {reg }}$ [see Fig. 12(b) and (e)] demonstrate $16.5 \%$ and $24.5 \%$ of the domain having significant differences over the period 1998-2010 and 2003-2016, respectively. In addition, $P$ values from trends of $D_{\text {ref }}$ versus $D_{\text {cci }}$ [see Fig. 12(d) and (h)] demonstrate $8.6 \%$ and $18.5 \%$ of the domain having significant differences during 1998-2010 and 2003-2016, respectively. The results demonstrated that the MDINEOF method performs better than concatenation and linear 


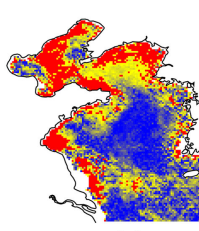

(a)

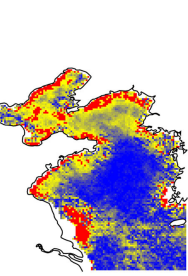

(e)

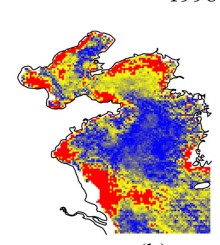

(b)

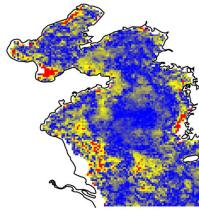

(c)

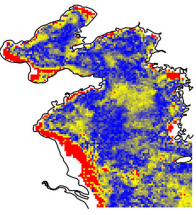

(d)
2003 - 2016

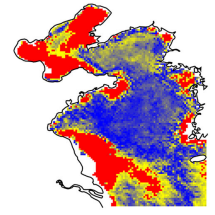

(f)

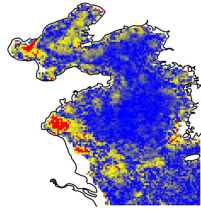

(g)

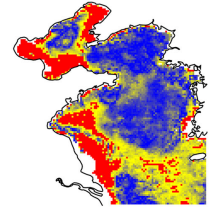

(h) \begin{tabular}{lllll}
\hline & & & & \\
0.05 & 0.2 & 0.4 & 0.6 & 0.8
\end{tabular}

Fig. 12. Level of significance $P$ of the $t$-test comparing the trends obtained for reference chl- $a$ datasets ( $\left.D_{\text {ref }}\right)$ versus four combined chl- $a$ datasets $\left(D_{\text {con }}\right.$, $D_{\text {reg }}, D_{\text {rec }}$, and $D_{\text {cci }}$ ) over the common period. (a) $D_{\text {ref }}$ versus $D_{\text {con }}$. (b) $D_{\text {ref }}$

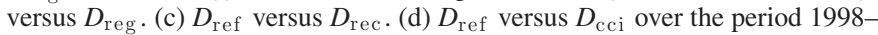

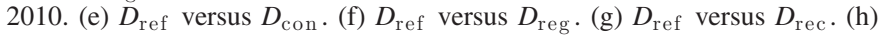
$D_{\text {ref }}$ versus $D_{\text {cci }}$ over the period 2003-2016.

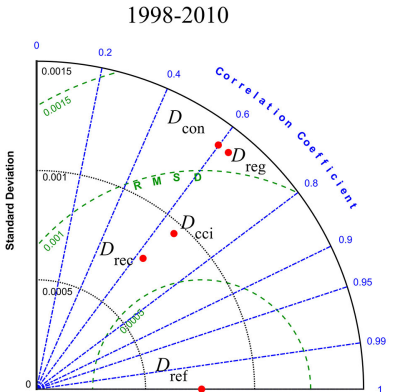

(a)

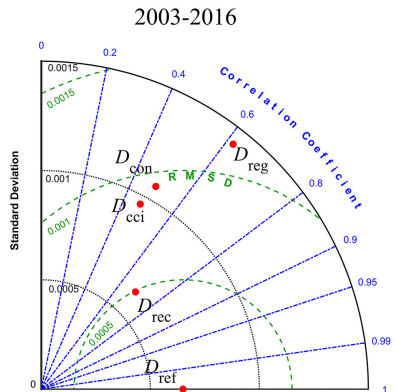

(b)
Fig. 13. Taylor diagrams expressing the relation of trends derived from different combined datasets $\left(D_{\text {con }}, D_{\text {reg }}, D_{\text {rec }}\right.$ and $\left.D_{\text {cci }}\right)$ with those from referenced datasets $\left(D_{\text {ref }}\right)$ over the period 1998-2010 and 2003-2016, respectively.

regression methods for combining the SeaWiFS and MODIS chl- $a$ datasets.

3) Taylor Diagram Comparison: To further quantify the overall agreement between trend patterns from different datasets, the Taylor diagrams were plotted in Fig. 13 to give visualized comparisons. The Taylor diagrams reveal that the trend pattern of $D_{\text {rec }}$ is obviously closer to that of $D_{\text {ref }}$ than those of $D_{\text {con }}, D_{\text {reg }}$, and $D_{\text {cci }}$. Compared with trends from $D_{\text {con }}$, $D_{\text {reg }}$, and $D_{\text {cci }}$, the $D_{\text {rec }}$ trend shows a more similar standard deviation, which is associated with lower RMSE and a higher correlation coefficient with respect to $D_{\text {ref }}$. The Taylor diagram result further confirmed that the M-DINEOF method performs better than the other three methods in creating multimission data records.

\section{Basin-Averaged Chl-a Series Comparisons}

The basin-averaged chl- $a$ series for different datasets over the validation periods are shown in Figs. 14 and 15. In the

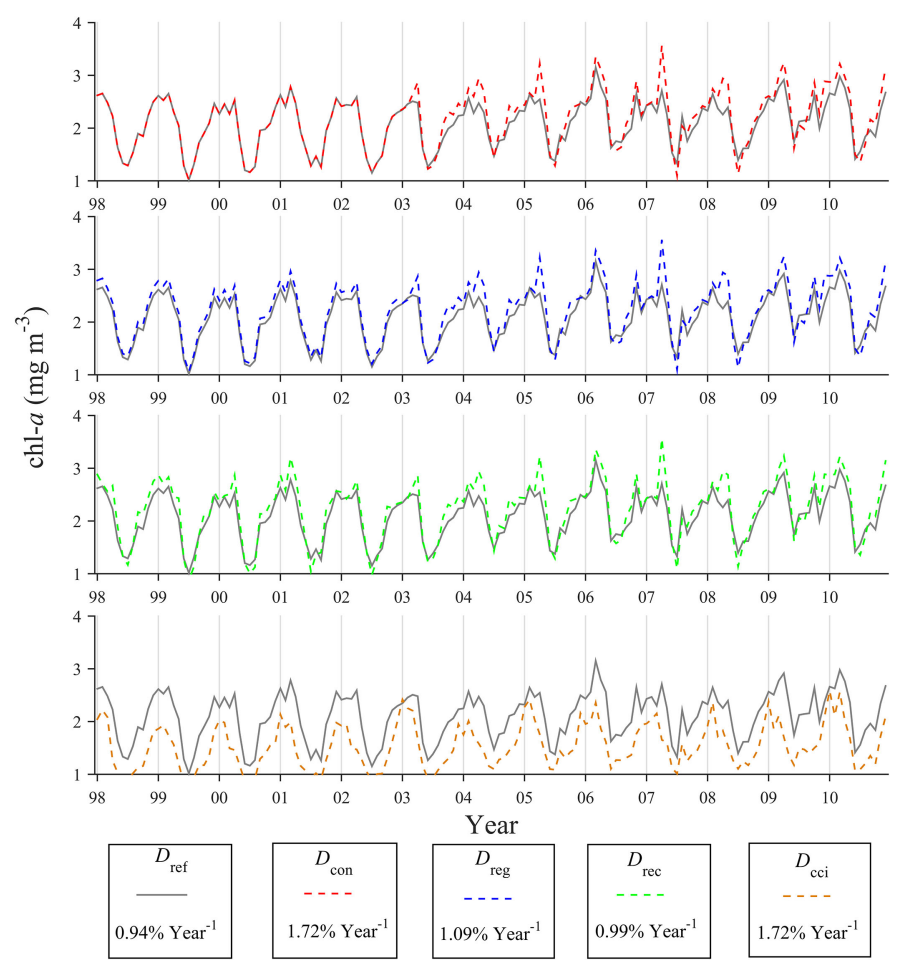

Fig. 14. Time series of basin-averaged chl- $a$ for $D_{\text {ref }}, D_{\text {con }}, D_{\text {reg }}, D_{\text {rec }}$, and $D_{\text {cci }}$ over the period 1998-2010. The trend of each chl- $a$ series is also given in the text at the bottom, respectively.
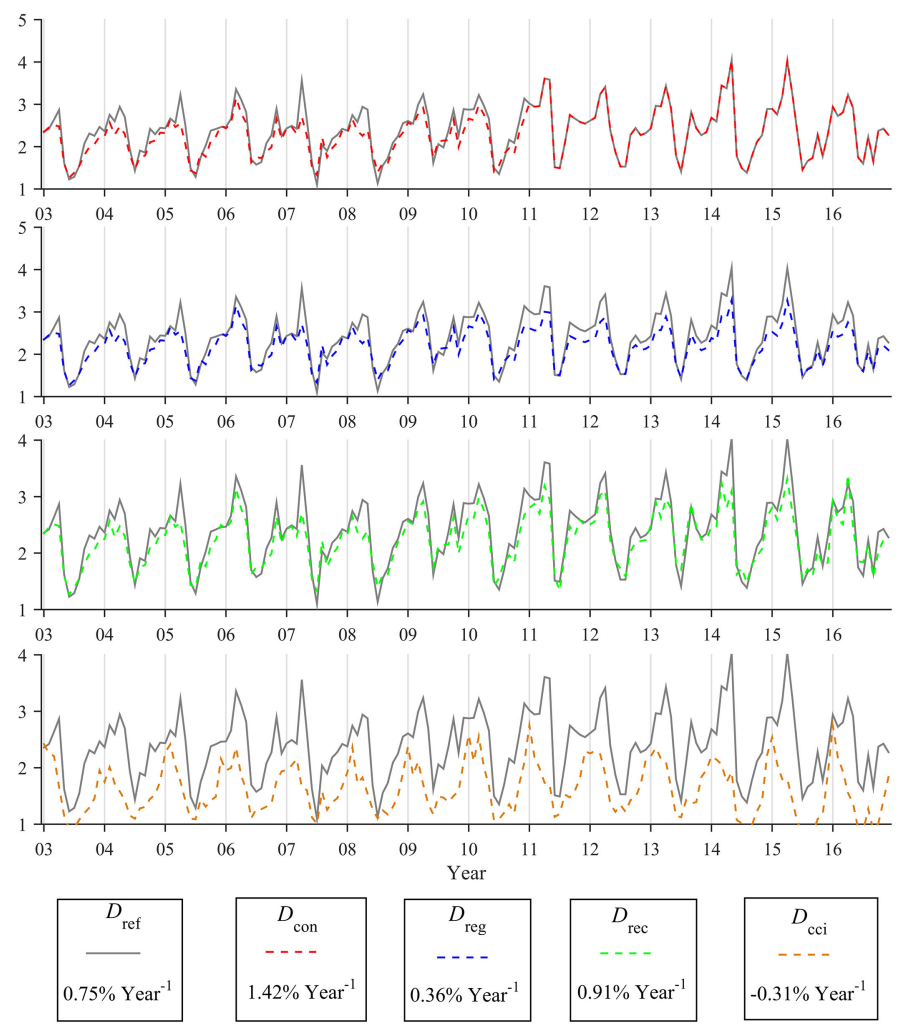

Fig. 15. Time series of basin-averaged chl- $a$ for $D_{\text {ref }}, D_{\text {con }}, D_{\text {reg }}, D_{\text {rec }}$ and $D_{\text {cci }}$ averaged over the period 2003-2016. The trend of each chl- $a$ series is also given in the text at the bottom, respectively. 


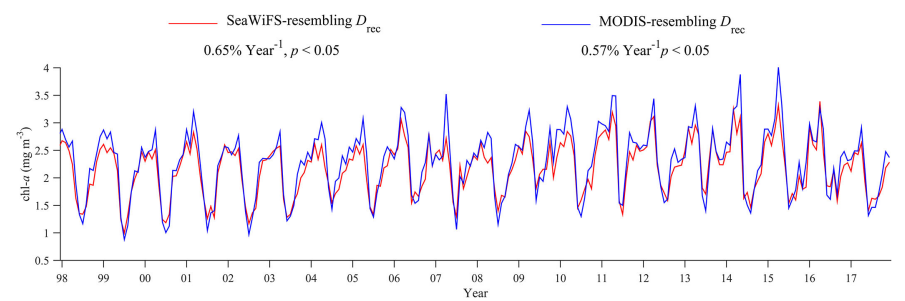

Fig. 16. Basin-averaged chl- $a$ series from M-DINEOF reconstruction for the SeaWiFS-resembled and MODIS-resembled datasets over the period from January 1998 to December 2017. The corresponding trends are shown in the texts.

view of the chl- $a$ variability, all the combined series ( $D_{\text {con }}$, $D_{\text {reg }}, D_{\text {rec }}$, and $D_{\text {cci }}$ ) present similar seasonal patterns as the reference series $\left(D_{\text {ref }}\right)$; there were extreme low chl- $a$ values during summer months, and there were high chl- $a$ values from autumn to the next spring, with a slight trough in winter. This was the typical chl- $a$ seasonal pattern over a temperate ocean [25], [40], [61]. However, the amplitudes of the chl- $a$ seasonal variability were slightly different between the combined series and reference series, which might explain the different trends that were estimated. During January 1998 to December 2010, the trend for $D_{\text {rec }}$ was $0.99 \% \mathrm{Year}^{-1}$, which is closer to the $D_{\text {ref }}$ than the other combined series $\left(1.72 \%\right.$ Year $^{-1}$ for $D_{\text {con }}, 1.09 \%$ Year ${ }^{-1}$ for $D_{\text {reg }}$, and $1.72 \%$ Year $^{-1}$ for $D_{\text {cci }}$ ) (see Fig. 14). During January 2003 to December 2016, the trend for $D_{\text {rec }}$ was $0.75 \%$ Year $^{-1}$, which is closer to the $D_{\text {ref }}$ than the other combined series $\left(1.42 \% \mathrm{Year}^{-1}\right.$ for $D_{\text {con }}, 0.36 \% \mathrm{Year}^{-1}$ for $D_{\text {reg }}$ and $-0.31 \%$ Year $^{-1}$ for $D_{\text {cci }}$ ) (see Fig. 15).

The basin-averaged chl- $a$ series over the entire study period from January 1998 to December 2017 for SeaWiFS-resembled and MODIS-resembled $D_{\text {rec }}$ were plotted in Fig. 16. Despite of the different magnitudes of chl- $a$ variabilities between them, the relative patterns were nearly consistent. Over the whole study period, the trend for the SeaWiFS-resembling $D_{\text {rec }}$ was $0.65 \%$ Year $^{-1}$ and the trend for the MODIS-resembling $D_{\text {rec }}$ was $0.57 \% \mathrm{Year}^{-1}$, which was not significantly different from each other $(P>0.91)$.

\section{DISCUSSION}

The consistency between the SeaWiFS and MODIS chl- $a$ datasets was examined through several statistical intercomparison analyses for their overlapped period of 2003-2010 in Section III-A. On one hand, the Pearson's correlation analysis demonstrates highly significant correlations between SeaWiFS and MODIS chl- $a$. This correlation is exactly the basics of the M-DINEOF implementation, which mainly relies on the relevant dynamics between input variables. On the other hand, the cross-mission biases between SeaWiFS and MODIS chl- $a$ were apparently nonlinear and unevenly distributed in the time and space domains. Consequently, both the direct concatenation and linear regression methods were insufficient in accounting for these cross-mission biases when combined for long-term trend analysis. Within their common operational period (2003-2010), the trends' estimates from the SeaWiFS and MODIS chl- $a$ series are quite consistent with each other (see Fig. 7). These results indicate that the chl- $a$ series from a sensor was stationary, and using the single mission chl- $a$ series as a reference series is feasible. Therefore, for trend comparisons between different chl- $a$ series, the constructed series using different combining methods from the SeaWiFS and MODIS chl- $a$ were directly compared with the single sensor data series for their trend evaluations. This validation scheme was efficient and was also widely used in previous studies for trend comparisons from different data series [29], [36], [37], [62]. Compared with other combined datasets, the OC-CCI chl- $a$ presents the least consistency with reference datasets in the BYS. This shows that OC-CCI chl- $a$, which was developed for global scale applications, may be problematic when being directly applied at regional scales. The various operational schemes for OC-CCI production, including band-shifting and bias-correction processes, which were trained on global observations, may induce new biases in local applications, especially over an optically complex coastal domain as BYS. Therefore, the OC-CCI chl- $a$ product needs to be thoroughly evaluated prior to regional applications.

The output datasets in M-DINEOF were produced by truncated EOF reconstruction. When the optimal number of EOF modes was determined by cross validation, the rest of the EOF modes were deemed as noise and discarded from the reconstruction. As a result, the M-DINEOF imposed a smoothing impact on the final reconstructed datasets. Consequently, some extreme events account for the little variance, but completely natural phenomenon may be filtered out as noises from the output datasets.

The main strength of M-DINEOF is the reconstruction of the data gaps along the time horizon in the benchmark dataset, thus relying on the relevant information from other missions. Therefore, the accuracy of the reconstructed datasets is highly dependent on the amount of their common observations. Namely, a longer length of their overlapped periods will produce more related information and likely a better accuracy. The M-DINEOF reconstruction produces a temporally and spatially continuous datasets. Not only was the time span extended, but also the spatial missing values were also filled. As a result, two temporally continuous and spatially complete chl- $a$ data records were constructed for the period of 1997-2017. One record resembles to SeaWiFS chl- $a$ with images from January 2011 to December 2017 inferred with the knowledge of MODIS chl- $a$; the other record resembles to MODIS chl- $a$ with images from September 1997 to July 2002 inferred with the knowledge of SeaWiFS chl- $a$. For long-term analysis, we recommend the SeaWiFSresembling dataset due to SeaWiFS being widely considered as having the highest quality sensor with the best match to in situ observations [37]. The results of Fig. 13 indicate that the trends from reconstructed dataset during the period of 2003-2017 are more consistent with the reference dataset than trends during the period of 1998-2010 (see Fig. 13).

Compared with other data merging methods which rely on complex bio-optical models and in situ measurements to eliminate these discrepancies, M-DINEOF seems more adaptive and effective because no a priori-determined basis functions and data-related parameters are required in the procedure. The M-DINEOF is an adaptive and effective method, as it only relies on common observations from multisensors. This trait means that the M-DINEOF method may be applied in a 
straightforward manner to other remote sensing variables in both ocean color remote sensing (such as the remote sensing reflectance or inherent optical properties) and in other fields (such as atmospheric ozone and $\mathrm{NO}_{2}$ concentrations). However, the quality of the reconstruction depends on the coherence/repeatability of the datasets being operated, which is itself a representation of natural processes but with discrete characteristics. Thus, low reconstruction quality estimates can occur when the natural process of the operational variables show low spatial and temporal coherency, e.g., extreme events with limited locations and/or with short durations might fail to be constructed by the EOF modes.

This study described a protocol to estimate the consistency of satellite chl- $a$ series via their monotonic trends with the objective of assessing the fitness-for-purpose of multimission datasets as the climate data record. We acknowledge that this indicator is a very crude descriptor of the long-term chl- $a$ variability in oceans [48], but such trends are indeed expected to appear in ocean chl- $a$ series over temporal scales. However, other signals such as the seasonal cycles and interannual fluctuations that were also present in long-term chl- $a$ series were not considered in our study [48]. Nevertheless, for sea surface chl- $a$ over temperate oceans, the seasonal and interannual signals always account for most of the total temporal variance, thus insusceptible to the cross-mission biases. Meanwhile, the trends' signals are relatively weaker and more vulnerable to the cross-mission biases.

In addition, in the original data source used in this study, we must bear in mind that the standard satellite chl- $a$ products show a poor performance due to complex water properties of the study area. However, in this study, the chl- $a$ was an example variable for the M-DINEOF operation. We used it to illustrate what degree the cross-mission biases can impact trend detection and how the M-DINEOF approach produces more accurate long-term reconstructions compared with the concatenate and regression methods. The objective of the study was not to derive accurate estimates of actual chl- $a$ trends in the ocean, as more accurate satellite chl- $a$ algorithms and advanced statistical methods are desirable. We also stress that presenting, interpreting, and understanding the observed trends were not among the objectives of this study.

\section{CONCLUSION}

The cross-mission biases between SeaWiFS and MODIS chl$a$ imposed a significant impact on chl- $a$ trend estimates over the BYS, despite the low magnitude of the biases. The common transition, including concatenation and linear regression methods, as well as global standard CCI merging approaches produced significantly different trend estimates between combined series and reference records over nearly $30 \%$ of the BYS.

In this study, we have extended the M-DINEOF approach to produce consistent and cloud-free chl- $a$ data records using the concurrent SeaWiFS and MODIS chl- $a$ datasets from 1997 to 2017. Compared with previous methods using complex bio-optical models and requiring much prior knowledge from previous training process, M-DINEOF is self-organized and more adaptive. This advantage makes the M-DINEOF technique transferable and applicable to other satellite variables with similar feature in various occasions.

As a result of the M-DINEOF reconstruction, spatially cloudfree and temporally continuous satellite chl- $a$ records were constructed over a longer operational period. More importantly, when concentrating on trends obtained from concatenated, linear regressed and CCI merged, M-DINEOF reconstructed chl- $a$ datasets, the M-DINEOF reconstructed chl- $a$ series produced the most similar trends as obtained from the reference series. Improved estimation of multiyear trends of sea surface chl- $a$ is crucial for our understanding of long-term changes in the ocean.

\section{ACKNOWLEDGMENT}

The authors would like to thank the Ocean Biology Processing Group of NASA for providing the SeaWiFS and MODIS dataset (http://oceancolor.gsfc.nasa.gov/).

\section{REFERENCES}

[1] S. C. Doney, D. M. Glover, S. J. McCue, and M. Fuentes, "Mesoscale variability of sea-viewing wide field-of-view sensor(SeaWiFS) satellite ocean color: Global patterns and spatial scales," J. Geophys. Res, Oceans, vol. 108, no. C2, 2003, Art. no. 3024.

[2] W. W. Gregg and N. W. Casey, "Global and regional evaluation of the SeaWiFS chlorophyll data set," Remote Sens. Environ., vol. 93 pp. 463-479, 2004.

[3] F. González Taboada and R. Anadón, "Seasonality of North Atlantic phytoplankton from space: impact of environmental forcing on a changing phenology (1998-2012)," Global Change Biol., vol. 20, pp. 698-712, 2014.

[4] W. W. Gregg and C. S. Rousseaux, "Decadal trends in global pelagic ocean chlorophyll: A new assessment integrating multiple satellites, in situ data, and models," J. Geophys. Res., Ocean, vol. 119, pp. 5921-5933, 2014.

[5] W. W. Gregg and R. H. Woodward, "Improvements in coverage frequency of ocean color: Combining data from SeaWiFS and MODIS," IEEE Trans. Geosci. Remote Sens., vol. 36, no. 4, pp. 1350-1353, Jul. 1998.

[6] D. Antoine, A. Morel, H. R. Gordon, V. F. Banzon, and R. H. Evans, "Bridging ocean color observations of the 1980s and 2000s in search of long-term trends," J. Geophys. Res., Oceans, vol. 110, 2005, Art. no. C06009.

[7] M. Marrari, A. R. Piola, D. Valla, and J. G. Wilding, "Trends and variability in extended ocean color time series in the main reproductive area of the Argentine hake, Merluccius hubbsi (Southwestern Atlantic Ocean)," Remote Sens. Environ., vol. 177, pp. 1-12, 2016.

[8] F. Mélin, G. Zibordi, and S. Djavidnia, "Merged series of normalized water leaving radiances obtained from multiple satellite missions for the Mediterranean Sea," Adv. Space Res., vol. 43, pp. 423-437, 2009.

[9] C. R. McClain, "A decade of satellite ocean color observations*," Annu. Rev. Mar. Sci., vol. 1, pp. 19-42, 2009.

[10] W. W. Gregg and N. W. Casey, "Sampling biases in MODIS and SeaWiFS ocean chlorophyll data," Remote Sens. Environ., vol. 111, pp. 25-35, 2007.

[11] W. W. Gregg and N. W. Casey, "Improving the consistency of ocean color data: A step toward climate data records," Geophys. Res. Lett., vol. 37, 2010, Art. no. L04605.

[12] C. Beaulieu et al., "Factors challenging our ability to detect long-term trends in ocean chlorophyll," Biogeosciences, vol. 10, pp. 2711-2724, 2013.

[13] R. J. W. Brewin, F. Mélin, S. Sathyendranath, F. Steinmetz, A. Chuprin, and M. Grant, "On the temporal consistency of chlorophyll products derived from three ocean-colour sensors," ISPRS J. Photogramm., vol. 97, pp. 171-184, 2014.

[14] S. V. V. Arun Kumar, K. N. Babu, and A. K. Shukla, "Comparative analysis of chlorophyll-a distribution from SeaWiFS, MODIS-Aqua, MODISTerra and MERIS in the Arabian Sea," Mar. Geodesy, vol. 38, pp. 40-57, 2014.

[15] A. Ali, S. E. Amin, H. H. Ramadan, and M. F. Tolba, "On using stacked neural network for multi-sensor data merging to enhance aerosol data assimilation," Neural Comput. Appl., vol. 23, no. 5, 2013, Art. no. 1521. 
[16] F. Mélin et al., "Multi-sensor satellite time series of optical properties and chlorophyll-a concentration in the Adriatic Sea," Prog. Oceanogr., vol. 91, pp. 229-244, 2011.

[17] S. Djavidnia, F. Mélin, and N. Hoepffner, "Comparison of global ocean colour data records," Ocean Sci., vol. 6, pp. 61-76, 2010.

[18] C. Zhang et al., "Bridging between SeaWiFS and MODIS for continuity of chlorophyll-a concentration assessments off Southeastern China," Remote Sens. Environ., vol. 102, pp. 250-263, 2006.

[19] S. Maritorena, O. H. F. d'Andon, A. Mangin, and D. A. Siegel, "Merged satellite ocean color data products using a bio-optical model: Characteristics, benefits and issues," Remote Sens. Environ., vol. 114, pp. 1791-1804, 2010.

[20] M. E. Conkright and W. W. Gregg, "Comparison of global chlorophyll climatologies: In situ, CZCS, Blended in situ -CZCS and SeaWiFS," Int. J. Remote Sens., vol. 24, no. 5, pp. 969-991, 2003.

[21] G. S. Fargion and C. R. McClain, "MODIS validation, data merger and other activities accomplished by the SIMBIOS Projec: 2002-2003," NASA/GSFC, Greenbelt, MD, USA, NASA TM-2003-212249, 2003.

[22] S. Maritorena and D. A. Siegel, "Consistent merging of satellite ocean color data sets using a bio-optical model," Remote Sens. Environ., vol. 94, pp. 429-440, 2005.

[23] F. Mélin and G. Sclep, "Band shifting for ocean color multi-spectral reflectance data," Opt. Express, vol. 23, pp. 2262-2279, 2015.

[24] N. P. Nezlin, I. G. Polikarpov, F. Y. Al-Yamani, D. V. Subba Rao, and A. M. Ignatov, "Satellite monitoring of climatic factors regulating phytoplankton variability in the Arabian (Persian) Gulf," J. Marine Syst., vol. 82, pp. 47-60, 2010.

[25] D. Liu and Y. Wang, "Trends of satellite derived chlorophyll-a (19972011) in the Bohai and Yellow Seas, China: Effects of bathymetry on seasonal and inter-annual patterns," Prog. Oceanogr., vol. 116, pp. 154-166, 2013.

[26] X. He et al., "Satellite views of the seasonal and interannual variability of phytoplankton blooms in the eastern China seas over the past $14 \mathrm{yr}$," Biogeosciences, vol. 10, pp. 4721-4739, 2013.

[27] B. A. Schaeffer, J. D. Hagy, and R. P. Stumpf, "Approach to developing numeric water quality criteria for coastal waters: Transition from SeaWiFS to MODIS and MERIS satellites," J. Appl. Remote Sens., vol. 7, 2013, Art. no. 073544.

[28] C. Pottier, V. Garcon, G. Larnicol, J. Sudre, P. Schaeffer, and P. Y. Le Traon, "Merging SeaWiFS and MODIS/Aqua ocean color data in North and Equatorial Atlantic using weighted averaging and objective analysis," IEEE Trans. Geosci. Remote Sens., vol. 44, no. 11, pp. 3436-3451, Nov. 2006.

[29] F. Mélin, "Impact of inter-mission differences and drifts on chlorophyll-a trend estimates," Int. J. Remote Sens., vol. 37, pp. 2061-2079, 2016.

[30] M. Kahru, R. M. Kudela, M. Manzano-Sarabia, and B. G. Mitchell, "Trends in the surface chlorophyll of the California Current: Merging data from multiple ocean color satellites," Deep-Sea Res. Pt. II, vol. 77-80, pp. 89-98, 2012.

[31] B. Saulquin, F. Gohin, and R. Garrello, "Regional objective analysis for merging high-resolution MERIS, MODIS/Aqua, and SeaWiFS chlorophyll-a data from 1998 to 2008 on the European Atlantic Shelf," IEEE Trans. Geosci. Remote Sens., vol. 49, no. 1, pp. 143-154, Jan. 2011.

[32] K. Bai, N.-B. Chang, and C.-F. Chen, "Spectral information adaptation and synthesis scheme for merging cross-mission ocean color reflectance observations from MODIS and VIIRS,' IEEE Trans. Geosci. Remote Sens., vol. 54, no. 1, pp. 311-329, Jan. 2016.

[33] A. Alvera-Azcárate, A. Barth, J. M. Beckers, and R. H. Weisberg, "Multivariate reconstruction of missing data in sea surface temperature, chlorophyll, and wind satellite fields," J. Geophys. Res., vol. 112, 2007, Art. no. C03008.

[34] J. M. Beckers and M. Rixen, "EOF calculations and data filling from incomplete oceanogr. datasets," J. Atmos. Ocean. Technol., vol. 20, pp. 1839-1856, 2003.

[35] A. Alvera-Azcárate, A. Barth, M. Rixen, and J. M. Beckers, "Reconstruction of incomplete oceanogr. data sets using empirical orthogonal functions: application to the Adriatic Sea surface temperature," Ocean Model., vol. 9, pp. 325-346, 2005.

[36] F. Mélin, V. Vantrepotte, A. Chuprin, M. Grant, T. Jackson, and S. Sathyendranath, "Assessing the fitness-for-purpose of satellite multimission ocean color climate data records: A protocol applied to OCCCI chlorophyll- a data," Remote Sens. Environ., vol. 203, pp. 139-151, 2017.

[37] A. Belo Couto, V. Brotas, F. Mélin, S. Groom, and S. Sathyendranath, "Inter-comparison of OC-CCI chlorophyll-a estimates with precursor data sets," Int. J. Remote Sens., vol. 37, pp. 4337-4355, 2016.
[38] W. Shi and M. Wang, "Satellite views of the Bohai Sea, Yellow Sea, and East China Sea," Prog. Oceanogr., vol. 104, pp. 30-45, 2012.

[39] H. Yamaguchi et al., "Seasonal and summer interannual variations of SeaWiFS chlorophyll a in the Yellow Sea and East China Sea," Prog. Oceanogr., vol. 105, pp. 22-29, 2012.

[40] H. Yamaguchi, J. Ishizaka, E. Siswanto, Y. B. Son, S. Yoo, and Y. Kiyomoto, "Seasonal and spring interannual variations in satelliteobserved chlorophyll-a in the Yellow and East China Seas: New datasets with reduced interference from high concentration of resuspended sediment," Continental Shelf Res., vol. 59, pp. 1-9, 2013.

[41] X. Wu, H. Duan, N. Bi, P. Yuan, A. Wang, and H. Wang, "Interannual and seasonal variation of chlorophyll-a off the Yellow River mouth (1997-2012): Dominance of river inputs and coastal dynamics," Estuaries, Coastal Shelf Sci., vol. 18, pp. 402-412, 2016.

[42] J. E. O'Reilly, S. Maritorena, and D. Siegel, "Ocean color chlorophyll a algorithms for SeaWiFS, OC2, and OC4: Version 4," NASA Goddard Space Flight Center, Greenbelt, MD, USA, 2000.

[43] CCI. Ocean Colour Climate Change Iinitiative Product User Guide, 2016, p. 57.

[44] CCI, "Ocean Colour Data Bias Correction and Merging, Ocean ColourClimate Change Initiative, Algorithm Theoretical Basis Document, Version 2.0," 2016, p. 57.

[45] Y. Wang and D. Liu, "Reconstruction of satellite chlorophyll-a data using a modified DINEOF method: A case study in the Bohai and Yellow seas, China," Int. J. Remote Sens., vol. 35, pp. 204-217, 2014.

[46] P. K. Sen, "Estimates of the regression coefficient based on Kendall's Tau," J. Amer. Statist. Assoc., vol. 63, pp. 1379-1389, 1968.

[47] R. O. Gilbert, Statistical Methods for Environmental Pollution Monitoring. New York, NY, USA: Van Nostrand Reinhold, 1987.

[48] V. Vantrepotte and F. Mélin, "Inter-annual variations in the SeaWiFS global chlorophyll a concentration (1997-2007)," Deep-Sea Res. Pt. I, vol. 58, pp. 429-441, 2011.

[49] S. Colella, F. Falcini, E. Rinaldi, M. Sammartino, and R. Santoleri, "Mediterranean ocean colour chlorophyll trends," PLoS One, vol. 11, 2016, Art. no. e0155756.

[50] R. M. Hirsch, J. R. Slack, and R. A. Smith, "Techniques of trend analysis for monthly water quality data," Water Resour. Res., vol. 18, pp. 107-121, 1982.

[51] R. Sokal Robert and R. F. James, Biometry. The Principles and Practice of Statistics in Biological Research. New York, NY, USA: Freeman, 1969.

[52] K. E. Taylor, "Summarizing multiple aspects of model performance in a single diagram," J. Geophys. Res. Atmos., vol. 106, pp. 7183-7192, 2001.

[53] P. Legendre. Model II Regression User's Guide, R Edition, (A tutorial within $R$ session, $R$ package lmodel2), 2008, p. 14.

[54] C. Hu, L. Feng, and Z. Lee, "Uncertainties of SeaWiFS and MODIS remote sensing reflectance: Implications from clear water measurements," Remote Sens. Environ., vol. 133, pp. 168-182, 2013.

[55] G. Meister, B. A. Franz, E. J. Kwiatkowska, and C. R. McClain, "Corrections to the calibration of MODIS aqua ocean color bands derived from SeaWiFS data," IEEE Trans. Geosci. Remote Sens., vol. 50, no. 1, pp. 310-319, Jan. 2012.

[56] J. E. O'Reilly et al., "Ocean color chlorophyll algorithms for SeaWiFS," J. Geophys. Res., Oceans, vol. 103, pp. 24937-24953, Oct. 1998.

[57] Y. B. Son, B.-J. Choi, Y. H. Kim, and Y.-G. Park, "Tracing floating green algae blooms in the Yellow Sea and the East China Sea using GOCI satellite data and Lagrangian transport simulations," Remote Sens. Environ., vol. 156, pp. 21-33, 2015.

[58] D. Y. Liu, J. K. Keesing, P. M. He, Z. L. Wang, Y. J. Shi, and Y. J. Wang, "The world's largest macroalgal bloom in the Yellow Sea, China: Formation and implications," Estuarine, Coastal Shelf Sci., vol. 129, pp. 2-10, 2013.

[59] C. M. Hu et al., "On the recurrent Ulva prolifera blooms in the Yellow Sea and East China Sea," J. Geophys. Res., Oceans, vol. 115, 2010, Art. no. C05017.

[60] Q. Xing et al., "World's largest macroalgal blooms altered phytoplankton biomass in summer in the yellow sea: Satellite observations," Remote Sens., vol. 7, pp. 12297-12313, 2015.

[61] F. Zhou, J. Xuan, D. Huang, C. Liu, and J. Sun, "The timing and the magnitude of spring phytoplankton blooms and their relationship with physical forcing in the central Yellow Sea in 2009," Deep-Sea Res. Pt. II, vol. 97, pp. 4-15, 2013.

[62] N. Sravanthi, P. Y. Ali, and A. C. Narayana, "Merging gauge data and models with satellite data from multiple sources to aid the understanding of long-term trends in chlorophyll-a concentrations," Remote Sens. Lett., vol. 8, pp. 419-428, 2017. 


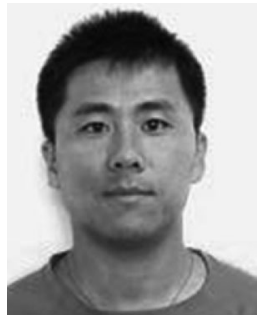

Yueqi Wang received the Ph.D. degree in environment science from the Yantai institute of Coastal Zone Research, Chinese Academy of Sciences, Yantai, China, in 2014.

$\mathrm{He}$ is currently an Assistant Professor with the Yantai Institute of Coastal Zone Research, Chinese Academy of Sciences. His research interests include ocean color remote sensing and its environmental applications.

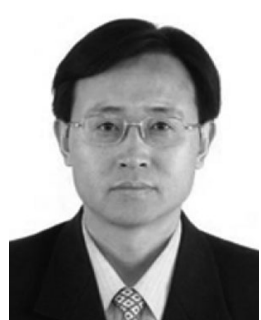

Zhiqiang Gao received the Ph.D. degree in mapping and geographic information system from the Institute of Remote Sensing Application, Chinese Academy of Sciences, Beijing, China, in 1998.

$\mathrm{He}$ is currently a Professor with the Yantai Institute of Coastal Zone Research, Chinese Academy of Sciences, Yantai, China. His current research interests include remote sensing application and model simulation in coastal zone.

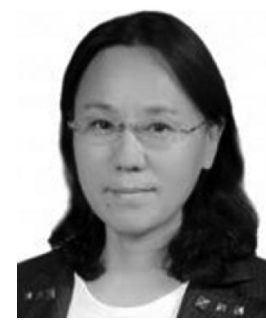

Dongyan Liu received the $\mathrm{Ph} . \mathrm{D}$. degree from the $\mathrm{Col}-$ lege of Chemistry and Chemical Engineering, Ocean University of China, Qingdao, China, in 2004.

Her research interests include ecology of marine phytoplankton and its response to global climate changes. 